\title{
Effects of chronic job insecurity and change in job security on self reported health, minor psychiatric morbidity, physiological measures, and health related behaviours in British civil servants: the Whitehall II study
}

\author{
J E Ferrie, M J Shipley, S A Stansfeld, M G Marmot
}

J Epidemiol Community Health 2002;56:450-454

See end of article for authors' affiliations

\section{Correspondence to Jane Ferrie, Department of Epidemiology and Public Health, University College London Medical School, 1-19 Torrington Place, London WCIE 6BT, UK; i.ferrie@public-health.ucl. ac.uk}

Accepted for publication 21 September 2001

\begin{abstract}
Study objective: To determine the effect of chronic job insecurity and changes in job security on self reported health, minor psychiatric morbidity, physiological measures, and health related behaviours. Design: Self reported health, minor psychiatric morbidity, physiological measures, and health related behaviours were determined in 931 women and 2429 men who responded to a question on job insecurity in 1995/96 and again in 1997/99. Self reported health status, clinical screening measures, and health related behaviours for participants whose job security had changed or who remained insecure were compared with those whose jobs had remained secure.

Setting: Prospective cohort study, Whitehall II, all participants were white collar office workers in the British Civil Service on entry to the study.

Main results: Self reported morbidity was higher among participants who lost job security. Among those who gained job security residual negative effects, particularly in the psychological sphere were observed. Those exposed to chronic job insecurity had the highest self reported morbidity. Changes in the physiological measures were limited to an increase in blood pressure among women who lost job security and a decrease in body mass index among women reporting chronic job insecurity. There were no significant differences between any of the groups for alcohol over the recommended limits or smoking.

Conclusion: Loss of job security has adverse effects on self reported health and minor psychiatric morbidity, which are not completely reversed by removal of the threat and which tend to increase with chronic exposure to the stressor.
\end{abstract}

$\mathrm{T}$ he effects of job insecurity on health have attracted only limited research interest. Studies can be divided into those that have examined self perceived job insecurity and those in which job insecurity has been externally attributed to downsizing or workplace closure. There is consistent evidence that perceived job insecurity has significant adverse effects on psychological morbidity and increasing evidence of similar effects on self reported physical health outcomes, but virtually no work has investigated effects on physiological measures. ${ }^{1}$ However, most studies to date have been cross sectional and so unable to explore the effects of prolonged exposure to perceived job insecurity or address the issue of change in perceived security over time.

A study over 14 months among car workers, found that job insecurity at baseline and follow up increased physical symptoms above the effects of job insecurity at any one point in time. Physical symptomatology was assessed using an index of 17 somatic symptoms such as persistent cough and frequent headaches. ${ }^{2}$ Similarly, a longitudinal study of public transport workers found continued exposure to job insecurity was associated with continuously high levels of psychological stress. ${ }^{3}$ However, data from a study in Finland indicate that job insecurity at baseline predicted job exhaustion at first follow up, which in turn predicted sickness absence at second follow up, but continued job insecurity at follow up had no further effect on either outcome. ${ }^{4}$

Although two longitudinal studies have examined transitions between job loss or unemployment and re-employment in an insecure job, ${ }^{56}$ there seems to be no published studies that have specifically examined change in perceived job security.
Data on perceived job insecurity were collected for the first time during the fourth data collection phase (Phase 4) of the Whitehall II study, a prospective study of British civil servants. The aim of the work presented in this paper was to examine the effect on self reported health, minor psychiatric morbidity, physiological measures, and health related behaviour at follow up (Phase 5) of chronic job insecurity and changes in job security over the 2.5 years separating the two phases. Women and men whose job security changed or whose job remained insecure were compared with participants securely employed at both time points.

\section{METHODS}

\section{Participants}

The target population for the Whitehall II study was all London based office staff, aged 35-55, working in 20 civil service departments. With a response rate of $73 \%$, the final cohort consisted of 10 308: 6895 men and 3413 women. ${ }^{7}$ The true response rate is higher, however, because around $4 \%$ of those invited were not eligible for inclusion. Although mostly white collar, respondents covered a wide range of grades from office support to permanent secretary.

\section{Data collection}

Baseline screening (Phase 1) took place between late 1985 and early 1988. This involved a clinical examination in which height, weight, blood pressure, and serum cholesterol were determined. A self administered questionnaire containing sections on demographic characteristics, health, lifestyle factors, work characteristics, social support, life events, and 
Table 1 Age standardised means and percentages (standard error) for morbidity and cardiovascular risk factors at follow-up (Phase 5) by job security status

\begin{tabular}{|c|c|c|c|c|}
\hline Women & $\begin{array}{l}\text { Continued security } \\
\text { Mean or \% (SE) }(n=435)\end{array}$ & $\begin{array}{l}\text { Insecure to secure } \\
\text { Mean or \% (SE) }(n=194)\end{array}$ & $\begin{array}{l}\text { Secure to insecure } \\
\text { Mean or \% (SE) }(n=116)\end{array}$ & $\begin{array}{l}\text { Chronic insecurity } \\
\text { Mean or \% (SE) ( } n=173)\end{array}$ \\
\hline Self rated health fair or poor (\%) & $11.4(2.0)$ & $11.9(2.5)$ & $15.3(2.7)$ & $22.6(3.7)$ \\
\hline Longstanding illness (\%) & $47.0(3.2)$ & $50.9(4.4)$ & $47.5(5.2)$ & $53.1(4.8)$ \\
\hline GHQ (30) score & $2.82(0.32)$ & $3.23(0.34)$ & $3.86(0.46)$ & $6.74(0.94)$ \\
\hline Depression score & $0.98(0.12)$ & $1.20(0.14)$ & $1.02(0.14)$ & $1.84(0.28)$ \\
\hline Cholesterol mmol/l & $5.88(0.07)$ & 6.09 (0.08) & $5.80(0.13)$ & $5.87(0.12)$ \\
\hline Systolic blood pressure $\mathrm{mm} \mathrm{Hg}$ & $121.6(1.2)$ & $121.9(1.7)$ & $124.9(3.1)$ & $116.4(1.7)$ \\
\hline Diastolic blood pressure $\mathrm{mm} \mathrm{Hg}$ & $75.5(0.6)$ & $75.7(1.0)$ & $77.3(1.4)$ & $73.2(0.9)$ \\
\hline Body mass index kg/m² & $26.5(0.4)$ & $27.6(0.6)$ & $26.4(0.5)$ & $25.6(0.5)$ \\
\hline Alcohol $\geqslant 15$ units/week (\%) & $15.5(2.0)$ & $13.2(2.5)$ & $10.9(4.4)$ & $18.3(3.7)$ \\
\hline www. publicationethics.org.uk & $10.4(1.9)$ & $14.1(3.4)$ & $9.4(2.3)$ & $20.8(4.4)$ \\
\hline \multicolumn{5}{|l|}{$\begin{array}{l}\text { This journal is a member of and } \\
\text { subscribes io the principles of the } \\
\text { Committee on Publication Ethics } \\
\text { Smoking }(\%)\end{array}$} \\
\hline Men & $(n=1261)$ & $(n=556)$ & $(n=209)$ & $(n=373)$ \\
\hline Self rated health fair or poor (\%) & $8.4(1.2)$ & $13.1(2.9)$ & $16.0(3.2)$ & $20.4(3.5)$ \\
\hline Longstanding illness (\%) & $45.2(2.1)$ & $48.1(3.7)$ & $45.0(4.2)$ & $51.4(4.3)$ \\
\hline GHQ (30) score & $2.02(0.16)$ & $3.21(0.42)$ & $3.27(0.37)$ & $5.05(0.55)$ \\
\hline Depression score & $0.62(0.05)$ & $1.11(0.16)$ & $1.21(0.13)$ & $1.56(0.16)$ \\
\hline Cholesterol mmol/l & $5.92(0.04)$ & $5.93(0.07)$ & $5.82(0.08)$ & $5.90(0.10)$ \\
\hline Systolic blood pressure mm Hg & $123.0(0.6)$ & $123.8(1.1)$ & $122.3(1.4)$ & $122.5(1.3)$ \\
\hline Diastolic blood pressure $\mathrm{mm} \mathrm{Hg}$ & $78.3(0.4)$ & $78.1(0.8)$ & $77.8(0.9)$ & $79.1(0.9)$ \\
\hline Body mass index $\mathrm{kg} / \mathrm{m}^{2}$ & $26.1(0.1)$ & $26.2(0.2)$ & $26.0(0.3)$ & $26.9(0.4)$ \\
\hline Alcohol $\geqslant 22$ units/week (\%) & 28.5 (1.9) & $31.0(3.5)$ & $32.3(3.8)$ & $30.4(4.1)$ \\
\hline Smoking (\%) & $8.7(1.1)$ & $10.9(2.5)$ & $6.6(1.9)$ & $10.2(2.3)$ \\
\hline
\end{tabular}

chronic difficulties was completed by each respondent. In 1989/90, (Phase 2), repeat questionnaire data were collected by post, and between 1992-1993 a further round of clinical screening and questionnaire data collection was completed (Phase 3). Phase 4, a postal questionnaire, was completed in 1995/6 and further screening and questionnaire data were collected between April 1997 and August 1999, Phase 5. Data for this work were derived from Phasel, Phase 4, and Phase 5.

\section{Measures}

Questionnaire items covered personal details: age and civil service employment grade; self reported morbidity: self rated health over the last year from the SF $36^{8}$ (fair or poor versus good, very good or excellent), presence of longstanding illness, and minor psychiatric morbidity, which was assessed using the 30-item General Health Questionnaire ${ }^{9}$ and comprised GHQ score and depression, measured using a 4-item depression subscale of the GHQ, derived by factor analysis; and health related behaviours: alcohol consumption over the recommended limits ( 15 or more units/week for women and 22 or more units/week for men), ${ }^{10}$ and smoking prevalence.

Negative affect or reporting bias was assessed at Phase 1 using the five negative affect items from Bradburn's Affect Balance Scale. ${ }^{11}$ Job insecurity was derived from a four category single item asked of those in civil service employment at Phase 4 and of all participants in employment at Phase 5 (How secure do you feel in your present job?). For the purpose of analysis, those whose job was insecure or very insecure were compared with participants whose job was secure or very secure.

\section{Physiological measures}

At the Phase 1 and Phase 5 screening examinations, blood pressure in millimetres of mercury $(\mathrm{mm} \mathrm{Hg})$ was measured twice with the participant seated after a five minute rest, using a Hawksley random-zero sphygmomanometer. Blood was taken and serum cholesterol concentration in millimoles/litre (mmol/l) measured using the cholesterol oxidase/peroxidase colorimetric method (BCL kit). Weight (wt) in kilograms and height (ht) in metres were recorded. Body mass index (BMI) was calculated from these two measures as wt/ht ${ }^{2}$. Further details of these measures have been reported previously. ${ }^{72}$

\section{Study sample and statistical analysis}

Of the 10308 respondents who participated in the baseline screening of the Whitehall II study 8629 (83\%) participated in Phase 4 and 7824 (76\%) at Phase 5. The 3685 participants eligible for inclusion in this paper were those in civil service employment at Phase 4 who were still working at Phase 5. Of these, 3360 responded to the job insecurity item in both the Phase 4 and Phase 5 questionnaires, 931 women and 2429 men.

The aim of the analysis was to compare self reported health, minor psychiatric morbidity, physiological measures, and health related behaviours at Phase 5 for participants whose job had remained secure (control group) with those for three exposure groups; participants who had lost or gained job security between Phases 4 and 5, and participants whose jobs were insecure at both time points (chronic insecurity).

For continuous variables, differences in self reported health, minor psychiatric morbidity, physiological measures, and health related behaviours at Phase 5 between participants in the exposure groups and those in the control group were assessed using analysis of covariance. Adjusted means and standard errors for all groups were produced by linear regression (GLM procedure in SAS). Results for continuous variables are presented by comparing the exposure group with the control group in terms of adjusted mean differences (Adj Diff) for the variable of interest and the standard error (SE) of the mean difference. For dichotomous variables, logistic regression (LOGIST in SAS) was used to compare Phase 5 self reported health, minor psychiatric morbidity, physiological measures, and health related behaviours in all groups. Results for the dichotomous variables are presented in terms of odds 
Table 2 Effects of loss or gain of job security and chronic job insecurity on morbidity and cardiovascular risk factors at follow-up (Phase 5), relative to continued security

\begin{tabular}{|c|c|c|c|c|c|c|}
\hline \multirow[b]{2}{*}{ Women* } & \multicolumn{2}{|l|}{ Insecure to secure } & \multicolumn{2}{|l|}{ Secure to insecure } & \multicolumn{2}{|l|}{ Chronic insecurity } \\
\hline & OR $(95 \% \mathrm{Cl})$ & $\mathrm{p}$ Value & OR $(95 \% \mathrm{Cl})$ & $\mathrm{p}$ Value & OR $(95 \% \mathrm{Cl})$ & $\mathrm{p}$ Value \\
\hline \multirow{3}{*}{$\begin{array}{l}\text { Self rated health fair or poor } \\
\text { Longstanding illness }\end{array}$} & 1.17 (0.7 to 2.0$)$ & $p=0.57$ & 1.80 (1.0 to 3.2$)$ & $p=0.05$ & 1.89 (1.2 to 3.1$)$ & $\mathrm{p}=0.01$ \\
\hline & 1.25 (0.8 to 1.9$)$ & $p=0.27$ & $1.66(1.0$ to 2.7$)$ & $p=0.04$ & $1.24(0.8$ to 1.9$)$ & $p=0.34$ \\
\hline & Diff $(95 \% \mathrm{Cl})$ & $\mathrm{p}$ Value & Diff $(95 \% \mathrm{Cl})$ & $\mathrm{p}$ Value & Diff $(95 \% \mathrm{Cl})$ & $\mathrm{p}$ Value \\
\hline $\mathrm{GHQ}(30)$ score & $0.97(-0.1$ to 2.0$)$ & $p=0.07$ & $1.71(0.5$ to 3.0$)$ & $p=0.008$ & $3.86(2.8$ to 5.0$)$ & $p<0.001$ \\
\hline Depression score & $0.30(0.0$ to 0.6$)$ & $p=0.07$ & $0.32(-0.1$ to 0.7$)$ & $p=0.12$ & $0.84(0.5$ to 1.2$)$ & $p<0.001$ \\
\hline Cholesterol mmol// & $0.09(-0.1$ to 0.2$)$ & $p=0.21$ & $-0.09(-0.3$ to 0.1$)$ & $\mathrm{p}=0.28$ & $-0.09(-0.2$ to 0.1$)$ & $p=0.24$ \\
\hline Systolic blood pressure $\mathrm{mm} \mathrm{Hg}$ & $1.09(-1.5$ to 3.7$)$ & $p=0.40$ & $3.57(0.5$ to 6.7$)$ & $p=0.02$ & $-0.93(-3.6$ to 1.7$)$ & $p=0.49$ \\
\hline Diastolic blood pressure $\mathrm{mm} \mathrm{Hg}$ & $0.13(-1.5$ to 1.7$)$ & $p=0.87$ & $1.76(-0.2$ to 3.7$)$ & $p=0.07$ & $-0.51(-2.2$ to 1.1$)$ & $p=0.53$ \\
\hline \multirow[t]{2}{*}{ Body mass index $\mathrm{kg} / \mathrm{m}^{2}$} & $0.17(-0.3$ to 0.7$)$ & $p=0.52$ & $-0.16(-0.8$ to 0.5$)$ & $p=0.61$ & $-0.53(-1.1$ to 0.0$)$ & $p=0.05$ \\
\hline & OR $(95 \% \mathrm{Cl})$ & $\mathrm{p}$ Value & OR $(95 \% \mathrm{Cl})$ & $\mathrm{p}$ Value & OR $(95 \% \mathrm{Cl})$ & $\mathrm{p}$ Value \\
\hline $\begin{array}{l}\text { Alcohol } \geqslant 15 \text { units/week } \\
\text { Smoking }\end{array}$ & $\begin{array}{l}0.91(0.5 \text { to } 1.5) \\
1.15(0.5 \text { to } 2.5)\end{array}$ & $\begin{array}{l}p=0.71 \\
p=0.72\end{array}$ & $\begin{array}{l}0.61(0.3 \text { to } 1.3) \\
1.27(0.5 \text { to } 3.1)\end{array}$ & $\begin{array}{l}p=0.18 \\
p=0.60\end{array}$ & $\begin{array}{l}1.35(0.8 \text { to } 2.3) \\
1.56(0.7 \text { to } 3.3)\end{array}$ & $\begin{array}{l}\mathrm{p}=0.26 \\
\mathrm{p}=0.26\end{array}$ \\
\hline Men* & OR $(95 \% \mathrm{Cl})$ & $\mathrm{p}$ Value & OR $(95 \% \mathrm{Cl})$ & $\mathrm{p}$ Value & OR $(95 \% \mathrm{Cl})$ & $\mathrm{p}$ Value \\
\hline \multirow{3}{*}{$\begin{array}{l}\text { Self rated health fair or poor } \\
\text { Longstanding illness }\end{array}$} & $1.12(0.8$ to 1.6$)$ & $p=0.53$ & 1.98 (1.3 to 3.1$)$ & $p=0.002$ & 2.18 (1.6 to 3.0$)$ & $p<0.001$ \\
\hline & $1.11(0.9$ to 1.4$)$ & $p=0.39$ & 0.95 (0.7 to 1.4 ) & $p=0.77$ & $1.19(0.9$ to 1.6$)$ & $p=0.20$ \\
\hline & Diff $(95 \% \mathrm{Cl})$ & $\mathrm{p}$ Value & Diff $(95 \% \mathrm{Cl})$ & $\mathrm{p}$ Value & Diff $(95 \% \mathrm{Cl})$ & $\mathrm{p}$ Value \\
\hline GHQ (30) score & 0.94 (0.4 to 1.5$)$ & $p<0.001$ & $1.61(0.9$ to 2.4$)$ & $p<0.001$ & $3.13(2.5$ to 3.7$)$ & $p<0.001$ \\
\hline Depression score & $0.24(0.1$ to 0.4$)$ & $p=0.004$ & $0.37(0.1$ to 0.6$)$ & $p=0.002$ & $0.72(0.5$ to 0.9$)$ & $p<0.001$ \\
\hline Cholesterol mmol/l & $0.03(-0.1$ to 0.1$)$ & $p=0.50$ & $-0.11(-0.2$ to 0.0$)$ & $p=0.08$ & $-0.07(-0.2$ to 0.0$)$ & $p=0.20$ \\
\hline Systolic blood pressure $\mathrm{mm} \mathrm{Hg}$ & $0.80(-0.6$ to 2.2$)$ & $p=0.24$ & $0.19(-1.8$ to 2.2$)$ & $p=0.85$ & $-0.14(-1.7$ to 1.4$)$ & $p=0.85$ \\
\hline \multirow{3}{*}{$\begin{array}{l}\text { Diastolic blood pressure } \mathrm{mm} \mathrm{Hg} \\
\text { Body mass index } \mathrm{kg} / \mathrm{m}^{2}\end{array}$} & $0.05(-0.9$ to 1.0$)$ & $p=0.92$ & $0.31(-1.1$ to 1.7$)$ & $p=0.67$ & $-0.23(-1.4$ to 0.9$)$ & $p=0.69$ \\
\hline & $0.19(0.0$ to 0.4$)$ & $p=0.08$ & $0.23(-0.1$ to 0.5$)$ & $\mathrm{p}=0.16$ & $0.06(-0.2$ to 0.3$)$ & $\mathrm{p}=0.64$ \\
\hline & OR $(95 \% \mathrm{Cl})$ & $\mathrm{p}$ Value & OR $(95 \% \mathrm{Cl})$ & $\mathrm{p}$ Value & OR $(95 \% \mathrm{Cl})$ & $\mathrm{p}$ Value \\
\hline Alcohol $\geqslant 22$ units/week & 1.14 (0.9 to 1.5$)$ & $p=0.30$ & $1.15(0.8$ to 1.7$)$ & $p=0.43$ & $0.85(0.6$ to 1.1$)$ & $p=0.29$ \\
\hline Smoking & $1.43(0.9$ to 2.3$)$ & $p=0.15$ & $0.69(0.3$ to 1.4$)$ & $p=0.32$ & 1.33 (0.8 to 2.3 ) & $p=0.30$ \\
\hline
\end{tabular}

ratios (ORs) for the variable of interest with 95\% confidence intervals (95\% CI). All analyses were adjusted sequentially for age at Phase 5, and employment grade and value of the measure of interest at Phase 1. Self reported health, minor psychiatric morbidity, physiological measures, and health related behaviours were also analysed unadjusted and adjusted for negative affect. Data were analysed using SAS version 6.12 for Windows. ${ }^{13}$

\section{RESULTS}

Table 1 presents the Phase 5 distribution of self reported health, minor psychiatric morbidity, physiological measures, and health related behaviours for control participants (continued secure employment) and participants in the three exposure groups: insecure at Phase 4 and secure at Phase 5; secure at Phase 4 and insecure at Phase 5; and insecure at both phases. The effects of these exposures on self reported health, minor psychiatric morbidity, physiological measures, and health related behaviours at Phase 5, relative to outcomes for control participants are presented in table 2. Analyses adjusted for negative affect produced results similar to those presented in table 2 (data not shown).

\section{Change from insecure to secure employment}

Relative to securely employed participants, poor self reported health, minor psychiatric morbidity, and adverse physiological measures were slightly more prevalent among women and men whose job was insecure at Phase 4, but secure by Phase 5 . Most differences were non-significant, with the exception of GHQ score $(p<0.001)$ and depression $(p=0.004)$ in men. Although the size of the effects for these measures was the same in women, small numbers reduced the strength of the association (both $\mathrm{p}=0.07$ ). Levels of minor psychiatric morbidity in this group, although higher than in control participants, were lower than in the other exposure groups.

\section{Change from secure to insecure employment}

Loss of job security between Phases 4 and 5 was associated with poor self rated health $(\mathrm{p}=0.002)$, higher GHQ score $(\mathrm{p}<0.001)$, and more depression $(\mathrm{p}=0.002)$ in men. These findings were replicated in women, but again small numbers reduced the strength of the associations, $\mathrm{p}=0.05, \mathrm{p}=0.008$ and $\mathrm{p}=0.12$ respectively. In women, higher relative levels of longstanding illness $(p=0.04)$, systolic $(p=0.02)$ and diastolic blood pressure $(\mathrm{p}=0.07)$ were also observed.

\section{Chronic job insecurity}

In both sexes chronic job insecurity was significantly associated with poor self rated health $(p \leqslant 0.01)$, and both measures of minor psychiatric morbidity $(p<0.001)$. Overall, self reported risk factors were higher in this group than any other group, but associations with the physiological measures were non-significant with the exception of an inverse association between chronic job insecurity and BMI in women $(\mathrm{p}=0.05)$.

There were no statistically significant differences between any of the groups for alcohol over the recommended limits or smoking.

\section{DISCUSSION}

\section{Methodological considerations}

Most previous studies of perceived job insecurity have been either cross sectional or have measured only repeated exposure to the stressor. This study examined changes in perceived security relative to a control group who remained in secure employment. Furthermore, health selection was 


\section{Key points}

- Most studies of job insecurity have been cross sectional and so unable to explore the effects of prolonged exposure or address issues of change over time.

- Data from a longitudinal study were used to examine exposure to job insecurity over 2.5 years, while controlling for morbidity from a prior phase of secure employment.

- Residual negative effects of job insecurity, particularly in the psychological sphere, were observed among workers who gained job security.

- Loss of job security was associated with increased self reported morbidity, while workers exposed to chronic job insecurity had the highest self reported morbidity.

- Job insecurity has adverse effects on health that are not completely reversed by removal of the threat and that increase with chronic exposure to the stressor.

reduced by controlling for the outcome of interest at baseline, and adjustment for negative affect indicated it was unlikely that associations could be attributed to reporting bias. The data available enabled us to determine perceived job security at the time of the Phase 4 and 5 questionnaires but provided no indication of intervening changes, subtleties of exposure this study was unable to capture.

A potential limitation of this study was the measurement of perceived job insecurity using a single item measure. It is now widely recognised that the definition of job insecurity as the threat of imminent job loss is too narrow in that it fails to include the threat from deteriorating employment conditions and career opportunities. ${ }^{14}$ However, qualitative data from a subsample of respondents included in these analyses showed that their personal definitions of job insecurity were not restricted to potential job loss. Interviewees described feelings of increased vulnerability when valued features of the job were threatened or removed and on being assigned unwanted additional tasks and responsibilities, including private sector practices, previously alien to civil servants..$^{15}$ These findings indicate that our single item captured a range of experiences despite failing to address individual components of the construct. We have looked elsewhere at the relation between job insecurity and other psychosocial work characteristics, such as work demands, which may act as partial proxies for aspects of the job insecurity construct (unpublished findings).

To ensure our findings for blood pressure and cholesterol were not confounded by clinical interventions, an additional set of analyses, which excluded participants on antihypertensive treatment ( 96 women and $207 \mathrm{men}$ ) and cholesterol lowering drugs ( 12 women and 68 men), were carried out (data not shown). Although the percentage of participants on drug treatment was consistently, though non-significantly, higher among participants who either lost job security or remained insecure, these analyses produced findings which were very similar to those shown in table 2. The largest change was for systolic pressure among untreated women where the difference for those who became insecure compared with the control group was $3.17 \mathrm{~mm} \mathrm{Hg}(-0.1$ to 6.5$) \mathrm{p}=0.06$.

As employment grade at Phase 1 was used to determine the gradients, our measure of socioeconomic position is not contemporaneous with our morbidity and risk factor measures at Phase 5. Baseline grade was chosen as it is available for all participants, and analyses using last known grade produced findings little different from those using grade at Phase 1 (data not shown). It was felt that use of last known grade as the measure of socioeconomic position posed problems in that it reflects mobility for those who remained in the civil service, but cut short the trajectories of those who left the civil service to take up employment elsewhere, 29\% of those in employment at Phase 5. Use of Phase 1 grade also minimised the effect of reverse causality where the levels of morbidity at baseline may affect subsequent mobility and hence grade at Phase 5.

\section{Findings}

In common with most work on perceived job insecurity, the findings of greatest note were in the psychological sphere. GHQ score and depression were higher in all three exposure groups relative to participants who remained in secure employment. The smallest difference was observed among participants who gained security, the greatest among those insecure at both Phases, while those who lost security fell between. Poor self rated health, which has a large subjective appraisal element, was also higher in women and men who either lost security or remained insecure, and the prevalence of longstanding illness was raised among women who lost job security. Differences in the physiological measures were few. Cholesterol displayed a tendency to be lower in all groups reporting job insecurity at Phase 5. Greater increases in blood pressure were seen in women who lost job security, and there was a lower BMI among women reporting chronic job insecurity.

\section{Change from insecure to secure employment}

Little research has examined effects on health of regaining job security having previously felt one's job to be insecure. A study in Sweden, which examined perceived job insecurity as a predictor, showed adverse effects on mental, but not physical health, one year later. ${ }^{14}$ Similar findings have been made in relation to attributed job insecurity, several studies of the survivors of downsizing having demonstrated effects on health after the job threat has been removed. ${ }^{16-18}$ Such observations, which seem to be confirmed in our findings, indicate that removal of the threat of job insecurity will not immediately remove the risk of raised morbidity.

\section{Change from secure to insecure employment}

Although little work has documented effects on health of loss of job security relative to a control group, our findings confirm those of numerous studies that have reported an association between perceived job insecurity and psychological morbidity. ${ }^{131920}$ The higher blood pressure and greater prevalence of longstanding illness in women who report a loss of job security reflect findings from longitudinal studies that have shown attributed job insecurity to be associated with increased sickness absence and health service use. ${ }^{172122}$ Furthermore, the relative difference in blood pressure is similar to that observed in another group of women in the Whitehall II cohort when faced with the imminent privatisation of their whole department. ${ }^{23}$

\section{Chronic job insecurity}

Associations between chronic job insecurity and poor self rated health and a greatly increased risk of minor psychiatric morbidity reflect evidence of chronicity from previous studies. ${ }^{23}$ Persistence of a chronic stressor may also maintain pre-existing chronic psychological distress and impede recovery. ${ }^{24}$

Previous work among Whitehall II participants has demonstrated a strong association between chronic attributed job insecurity and increased BMI in both sexes, but associations with minor psychiatric morbidity were few. ${ }^{25}$ In the present analyses, however, chronic perceived job insecurity in women was associated with a lower BMI, but high GHQ 30 and depression scores. These findings may represent short-term physiological responses to chronic psychological distress typified by anxiety and reduced dietary intake. Any effects of chronic job insecurity in raising levels of morbidity and risk factors and increasing mortality risk may have a much longer time course than that observed in this study.

In general, findings among women were very similar to those for men, although the smaller number of women tended 
to reduce the strength of associations. Exceptions to this were associations between loss of security and longstanding illness and blood pressure, and between chronic job insecurity and BMI, both in women. In our previous work loss of job security attributed to forthcoming privatisation was accompanied by a significant increase in job demands in women and a significant loss of skill discretion in men. Such sex specific adverse changes in other characteristics of the work environment may explain the slight gender differences seen in this study. In the case of the association between chronic insecurity and BMI, it is also possible that chronic anxiety is more likely to result in changes in dietary intake in women.

\section{Generalisability of findings}

The generalisability of findings from occupational cohorts is limited by the participants, often a relatively homogeneous group working in one field or organisation. Similarly, in this study, all respondents were office based, white collar civil servants at baseline screening. Civil servants made up approximately $2 \%$ of the workforce in the UK in $1998 .{ }^{26}$ Many civil servants are engaged in providing services to the general public, such as paying pensions and issuing driving licences. Others provide advice and information to ministers in support of the development and implementation of policy, including legal, statistical, and economic issues. In addition to specialists, the civil service employs large numbers of administrators and general office staff. Thus, in its structure and functions the civil service resembles many other office settings, for example financial services in the private sector and corporations in the public sector. Also, by Phase 5, 29\% of those in employment were working outside the civil service, a factor likely to increase generalisability to other white collar workforces in mid-career to late career.

\section{Conclusion}

Compared with those who remained in secure employment, self reported morbidity was raised among participants who lost job security at follow up. Among those who gained job security some residual effects of job insecurity, particularly in the psychological sphere were observed. Those exposed to chronic job insecurity had the greatest self reported morbidity, indicating that perceived job insecurity acts as a chronic stressor with regard to these factors. However, there were few changes in the physiological measures.

\section{ACKNOWLEDGEMENTS}

We thank all participating civil service departments and their welfare, personnel, and establishment officers; the Occupational Health and Safety Agency; the Council of Civil Service Unions; all participating civil servants in the Whitehall II study; and all members of the Whitehall II study team.

\section{Contributors}

Jane Ferrie wrote the original and successive drafts of the paper and was involved in the data collection for Phase 5. Martin Shipley performed the analyses and advised on drafts of the paper. Stephen Stansfeld was involved with the data collection and commented on drafts of the paper. Michael Marmot designed and directs the Whitehall II study and commented on drafts of the paper.

\section{Authors' affiliations}

J E Ferrie, M J Shipley, M G Marmot, International Centre for Health and Society, Department of Epidemiology and Public Health, University College London Medical School, UK

S A Stansfeld, Department of Psychiatry, Queen Mary University of London, UK
Funding: the Whitehall II study has been supported by grants from the Medical Research Council; British Heart Foundation; Health and Safety Executive; Department of Health; National Heart Lung and Blood Institute (HL36310), US, NIH: National Institute on Aging (AG13196), US, NIH; Agency for Health Care Policy Research (HSO6516); and the John D and Catherine T MacArthur Foundation Research Networks on Successful Midlife Development and Socio-economic Status and Health. JF was supported by the Economic and Social Research Council (L128251046) during the preparation of this paper. MM is supported by an MRC Research Professorship. MS is supported by the British Heart Foundation.

Conflicts of interest: none.

\section{REFERENCES}

1 Ferrie JE. Is job insecurity harmful to health? J R Soc Med $2001 ; 94: 71-6$.

2 Heaney C, Israel B, House J. Chronic job insecurity among automobile workers: effects on job satisfaction and health. Soc Sci Med 1994;38: $1431-7$

3 Dekker SWA, Schaufeli WB. The effects of job insecurity on psychological health and withdrawal: a longitudinal study. Australian Psychologist 1995;30:57-63.

4 Kinnunen U, Mauno S, Natti J, et al. Perceived job insecurity: a longitudinal study among Finnish employees. European Journal of Work and Organisational Psychology 1999;8:243-60.

5 Burchell B. The effects of labour market position, job insecurity, and unemployment on psychological health. In: Gallie D, Marsh C, Vogler C, eds. Social change and the experience of unemployment. Oxford: Oxford University Press, 1994:188-212.

6 Ferrie JE, Martikainen P, Shipley M, et al. Employment status and health after privatisation in white collar civil servants: prospective cohort study. BM 2001;322:647-51.

7 Marmot MG, Davey Smith G, Stansfeld S, et al. Health inequalities among British civil servants: the Whitehall II study. Lancet 1991;337:1387-93

8 Ware JE, Kosinski M, Keller SD. SF-36 physical and mental summary scales: a user's manual. Boston, MA: The Health Institute, 1994.

9 Goldberg DP. The detection of psychiatric illness by questionnaire. London: Oxford University Press, 1972.

10 OPCS Social Survey Division. General Household Survey 1982. London: HMSO, 1984.

11 Bradburn NM. The structure of psychological wellbeing. Chicago: Aldine, 1969

12 Rose G, Hamilton PS, Keen $\mathrm{H}$, et al. Myocardial ischaemia, risk factors and death from coronary heart-disease. Lancet 1977; 1:105-9.

13 SAS Institute Inc. SAS language reference. Version 6. 1st edn. Cary, NC: SAS Institute, 1990

14 Hellgren J, Sverke M, Isaksson K. A two-dimensional approach to job insecurity: consequences for employee attitudes and well-being. European Journal of Work and Organisational Psychology 1999:8:179-95

15 Marmot M, Ferrie J, Newman K, et al. The contribution of job insecurity to socio-economic inequalities. Research FINDINGS 11 from the Health Variations Programme. Lancaster: Economic and Social Research Council, 2001.

16 Armstrong-Stassen $\mathbf{M}$. The impact of organisational downsizing on the job satisfaction of nurses. Canadian Journal of Nursing Administration 1996;9:8-32.

17 Vahtera J, Kivimaki M, Pentti J. Effect of organisational downsizing on health of employees. Lancet 1997;350:1 124-8.

18 Grunberg L, Moore SY, Greenberg ES. Differences in psychological and physical health among layoff survivors: the effect of layoff contact Journal of Occupational Health Psychology $2001 ; 6: 15-25$.

19 Dooley D, Rook K, Catalano R. Job and non-job stressors and their moderators. Journal of Occupational Psychology 1987;60:1 15-32.

20 De Witte H. Job insecurity and psychological well-being: review of the literature and exploration of some unresolved issues. European Journal of Work and Organisational Psychology 1999;8:155-77.

21 Jacobsen K. Afskedigelse og sygelighed. Ugeskr Laeg 1972;134:352-4.

22 Beale $\mathbf{N}$, Nethercott S. Job-loss and family morbidity: a study of a factory closure. J R. Coll Gen Pract 1985;35:510-14.

23 Ferrie JE, Shipley M, Marmot MG, et al. An uncertain future: the health effects of threats to employment security in white-collar men and women. Am J Public Health 1998;88:1030-6.

24 Weich S, Lewis G. Poverty, unemployment, and common mental disorders: population based cohort study. BM 1998;317:1 15-19.

25 Ferrie JE, Shipley M, Marmot MG, et al. Job insecurity in white-collar workers: Towards an explanation of associations with health. Journal of Occupational Health Psychology $2001 ; 6: 26-42$

26 Government Statistical Service. Civil Service Statistics 1999. London: Cabinet Office, 2000 